\title{
THE INDENTATION SIZE EFFECT AND ITS ROLE IN MICROHARDNESS MEASUREMENTS OF TWO VISCOELASTIC MATERIALS UNDER DIFFERENT LOADS AND TIMES
}

\author{
Ramy Abdallah Abdel Rahim * and Eman M. S. Elbahrawy**
}

\begin{abstract}
Background: Vickers and knoop hardness tests have been used to determine the viscoelastic materials resistance to local plastic deformation in scientific community. The existence of the indentation size effect (ISE) implies that, if hardness is used as a materials selection characterization, it is clearly insufficient to cite a single hardness number, since using a load-dependent hardness number in material characterization may result in some unreliable conclusions. However, it is of crucial importance to fully understand the influence of the indentation load for different time, since its value influences the obtained result. Aim of Study: The aim of this study was to evaluate the effect of indentation size under different loads and times on microhardness values of two viscoelastic restorative materials by using Vickers and Knoop microhardness tests. Material and Methods: In this paper, two commercial viscoelastic restorative materials; resin composite and resin modified glass ionomer (RMGIC), have been tested. Vickers and Knoop micro-indentation with different loads (100, 200 and $300 \mathrm{~g}$ ) and different times (10, 20 and 30 seconds) has been used to assess the materials microhardness. Results: Two-way ANOVA statistical analysis followed by Tukey's test was used to determine the statistical differences between various groups. There are statistically significant differences ( $\mathrm{p} £ 0.05)$ at different indentation loads for both of VHN and KHN of composite and only VHN of resin modified GIC while, KHN of RMGIC was none significant (load-independent hardness). It was found that the optimal load and time for determining hardness in both tested viscoelastic materials are difficult to determined. This value may be regarded as loading independent hardness $\left(H_{L I H}\right)$. At lower loads, a more or less pronounced indentation size effect was noticed, while at higher loads and time, an unreliable indentation measurement and therefore an unreliable microhardness result.
\end{abstract}

KEYWORDS: Vickers, Knoop, microhardness, indentation size effect, viscoelastic materials.

\section{INTRODUCTION}

Microhardness test is a convenient method of investigating the mechanical properties of the surface of solid materials ${ }^{(1)}$. This method is easy, quick, and requires only a small area of solid sample surface for testing ${ }^{(2)}$.

The conventional procedure of hardness testing consists of applying a fixed load on the specimen surfaces with a diamond indenter for a fixed time. The diagonal of the resultant indentation on the surface of the test material were measured after unloading is done with the help of an optical microscopy ${ }^{(2,3)}$.
The Vickers indenter is the most common indenter geometry that can use in testing of surface hardness of the solid material ${ }^{(4)}$. The Vickers hardness number $(V H N)$ was defined by the ratio between the indentation load $(P)$ and the area of the residual indentation impression $(A)$, which depended on the indenter shape ${ }^{(5)}$.

Gutierrez \& Reyes ${ }^{(6)}$ reported that measuring of hardness by Knoop method is preferred because, Knoop indentation is longer and shallower than Vickers indentation, so a load impression can be applied to brittle materials without cracking. Plus, the longer diagonal is easier to read than the short diagonal of the Vickers.

\footnotetext{
* Lecturer, Faculty of Dental Medicine, Al-Azhar University, Dental Biomaterials Department.

** Lecturer, Faculty of Dentistry, Tanta University, Dental Biomaterials Department
} 
The hardness number $(H N)$ of materials was calculated using these equations:

$$
H=\frac{P}{A}=k \frac{P}{d^{2}} H=\frac{P}{A}=k \frac{P}{d^{2}}
$$

where $(d)$ is the measured length of indentation diagonal in $(\mu \mathrm{m})$ and $(k)$ is a constant equal to 1.8555 for Vickers hardness testing and 14.229 for Knoop hardness testing; was calculated from the specific geometry of the indenter ${ }^{(2,5)}$.

Theoretically the hardness Vicker (HV) and hardness Knoop(HK) values of microhardness should be constant when different load applied on the same sample, because when the applied load increases the resultant indentation size will also increase (2). However, the results of many researches that use different loads showed that the microhardness values vary with different load i.e. it is load dependent especially with low loads ${ }^{(7-9)}$.

Petrík et ${ }^{(10)}$., claimed that the advantage of Vickers test is, in contrast to the (macro) hardness, the Vickers hardness number is load-independence, because various diagonals indentations have similar geometry. Other investigations have confirmed that the hardness number calculated with equation (1) is usually depends on the applied load ${ }^{(7-9)}$.

The gradual decreasing in the measured hardness with increasing load can be observed for the same examined material i.e. when a very low load is used, the measured hardness is usually high; with an increase in test load, the measured hardness decreases. Such a phenomenon is frequently referred to as the "normal" Indentation size effect (ISE) ${ }^{(4,10)}$.

This characteristic may be attributed to the viscoelastic nature of the material and its elastic recovery $^{(11,12)}$, indentation cracks $^{(9)}$, surface texture ${ }^{(13)}$, or diagonal measurement errors as a result of the limitations of the resolution of the objective lens, inadequate measurement capability of small areas of indentations ${ }^{(13,14)}$.

The value of microhardness may increase with increasing the applied load, this phenomenon known as a "reversed "indentation size effect (RISE). Such a phenomenon is essentially occurring in materials in which plastic deformation is predominant, while the "normal" ISE takes place in brittle materials ${ }^{(15)}$.

The aim of the present work is to investigate the load and time dependence of the measured Vickers and Knoop hardness of two viscoelastic restorative materials with different plastic deformation and elastic recovery due to the different composition.

\section{MATERIALS AND EXPERIMENTAL METHODS}

\section{Materials:}

The materials chosen for this study are Filtek Z350, resin composite and Riva light cure RMGIC as two chemically different viscoelastic restorative materials. The materials chosen for this study are listed in Table (1).

TABLE (1) Materials composition and manufacturer.

\begin{tabular}{|c|c|c|}
\hline Materials & Composition & Manufacturer \\
\hline $\begin{array}{l}\text { Filtek Z350, Resin } \\
\text { composite }\end{array}$ & $\begin{array}{l}\text { - BIS-GMA, BIS-EMA, UDMA, TEGDMA resin. } \\
\text { - Non-agglomerated/non-aggregated } 20 \mathrm{~nm} \text { silica filler. Non-agglomerated/non- } \\
\text { aggregated } 4 \text { to } 11 \mathrm{~nm} \text { zirconia filler, and aggregated zirconia/silica cluster } \\
\text { filler (comprised of } 20 \mathrm{~nm} \text { silica and } 4 \text { to } 11 \mathrm{~nm} \text { zirconia particles). } \\
\text { - Shade A3E. }\end{array}$ & $\begin{array}{l}\text { Filtek Z350, 3M. } \\
\text { ESPE, USA. }\end{array}$ \\
\hline $\begin{array}{c}\text { Riva Light Cure } \\
\text { Resin-modified GIC }\end{array}$ & $\begin{array}{l}\text { - Polyacrylic acid } 15-25 \mathrm{wt} . \% \text {. } \\
\text { - Tartaric acid 1-5 wt. } \% \text {. } \\
\text { - } 2 \text {-Hydroxyethyl Methacrylate } 20-25 \mathrm{wt} . \% \text {. } \\
\text { - Acidic monomer } 10-20 \mathrm{wt} . \% \text {. } \\
\text { - Fluoroaluminosilicate glass powder } 95-100 w t . \% \text {. } \\
\text { - Shade A3. }\end{array}$ & $\begin{array}{l}\text { Riva Light Cure } \\
\text { [SDI], Australia. }\end{array}$ \\
\hline
\end{tabular}




\section{Specimen preparation:}

Twenty composite specimens and twenty RMGIC specimens were prepared. Each test specimen was prepared in Teflon mold at a size of $6 \mathrm{~mm}$ (diameter) $3 \mathrm{~mm}$ (thickness). A polyester transparent strip was placed over the top and bottom of the mold and pressed from top with a glass slide to form a flat surface of the samples. All samples were light-polymerized with the help of light-emitting diode (LED) curing light (Dentsply, York, PA, USA) with light intensity of $750 \mathrm{~mW} / \mathrm{cm}$ was held rigidly and placed zero distance over the glass slide for 40 seconds to polymerize the samples from both sides. Furthermore, the surface of the test specimen was polished with \#150,\#400, \#600,\#1200, and \#2000 grit water-proof abrasive papers ${ }^{(16,17)}$.

Ten composite specimens and ten RMGIC specimens were used for a Vickers microhardness test; the other ten composite and ten RMGIC specimens were used for a Knoop microhardness test.

\section{Test conditions:}

The measurements were performed at room temperature by using Vickers and Knoop microhardness tester (Zwic Roell, west Midlands, England) at different applied test load between 100, 200 and $300 \mathrm{~g}$, were used to examine the effect of difference of loading on the tested specimens, and load holding time was set to 10, 20 and 30 seconds for each composite and RMGIC specimen ${ }^{[2]}$. The VHN and KHN of both composite and RMGIC were calculated by using the following equations:

$$
H v=\frac{1.8544 \times p}{d^{2}} H v=\frac{1.8544 \times p}{d^{2}} \text { For }
$$

Vickers microhardness

Or

$H k=\frac{1.4230 \times p}{d^{2}} H k=\frac{1.4230 \times p}{d^{2}}$

For Knoop microhardness
Each test condition with the different applied test load $(100,200$ and $300 \mathrm{~g})$ and same time (10, 20 or 30 seconds) was conducted three times; thus, there were 9 indentations on each specimen surface obtained from different test loads and one times. An average of three readings for each test condition was recorded as the KHN or VHN value of a specimen. Data of each experimental condition from ten specimens were averaged, and differences in $\mathrm{KHN}$ or VHN values were compared using twoway ANOVA followed by a Tukey test.

\section{RESULTS}

A group of Vickers indentations on composite and Knoop indentations on resin modified GIC at different loads and times are shown in Figure (1).

The results of the Vickers and Knoop hardness tests for composite and RMGIC specimens at different test loads (100, 200 and $300 \mathrm{~g}$ ) and times (10, 20 and 30 seconds) are shown in Figure (2). For composite, the average VHN values are in the range of $42-61$ g. $\mathrm{mm}^{-2}$, while KHN values are in the range of $35-80 \mathrm{~g} \cdot \mathrm{mm}^{-2}$. For RMGIC, under the same testing conditions, the data shows without confusion that VHN values, which varied from 34 to $58 \mathrm{~g} . \mathrm{mm}^{-2}$, are higher than KHN values, which varied from 29 to 49 g. $\mathrm{mm}^{-2}$.

In Table (2), two-way ANOVA analysis of variance revealed statistically significant differences $(\mathrm{p} £ 0.05)$ at different indentation loads for both of VHN and KHN of composite and only VHN of resin modified GIC while, KHN of RMGIC was none significant (load-independent hardness).

Multiple comparison with a Tukey's test revealed that for various loading times the average VHN values of composite was statistically significant, while, no statistically significant differences between 200 and $300 \mathrm{~g}$ loads.

However, for KHN value of composite there were no statistically significant difference for various loading times (time independent deformation). 
While, there was statistically significant differences between 100 and $300 \mathrm{~g}$ loads.

For VHN of RMGIC the only statistical significant difference for various loading times was found between 20 and 30 seconds. While, no statistically significant differences between 100 and $200 \mathrm{~g}$ loads.

However, there were no statistically significant differences of KHN values in RMGIC at different loads and time.
Evidently, the Vickers hardness is a function of the applied load at indentation test load. Both of "normal" indentation size effect (ISE) and "reversed" indentation size effect (RISE) can be clearly seen through, Vickers and Knoop hardness at different applied loads and times.

The existence of ISE makes it unsatisfactory here to cite a single hardness value when Vickers hardness is used for material characterization.

TABLE (2) Multiple Comparisons, Tukey's test

\begin{tabular}{|c|c|c|c|c|c|c|c|c|c|c|c|}
\hline \multicolumn{2}{|c|}{ Test Name } & (I) time & (J) time & $\begin{array}{c}\text { Mean } \\
\text { Difference (I-J) }\end{array}$ & Std. Error & Sig. & $\begin{array}{l}\text { (I) } \\
\text { load }\end{array}$ & $\begin{array}{l}(\mathrm{J}) \\
\text { load }\end{array}$ & $\begin{array}{c}\text { Mean } \\
\text { Difference (I-J) }\end{array}$ & Std. Error & Sig. \\
\hline \multirow{6}{*}{$\begin{array}{l}\frac{n}{0} \\
\frac{0}{0} \\
j\end{array}$} & \multirow{3}{*}{ 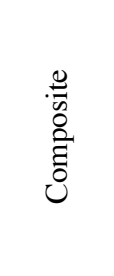 } & $10 \mathrm{sec}$ & $\begin{array}{l}20 \mathrm{sec} \\
30 \mathrm{sec}\end{array}$ & $\begin{array}{c}4.0667^{*} \\
-2.4667^{*}\end{array}$ & $\begin{array}{l}.86837 \\
.86837\end{array}$ & $\begin{array}{l}.000 \\
.020\end{array}$ & $100 \mathrm{~g}$ & $\begin{array}{l}200 \mathrm{~g} \\
300 \mathrm{~g}\end{array}$ & $\begin{array}{l}-2.7333^{*} \\
-4.0667^{*}\end{array}$ & $\begin{array}{l}.86837 \\
.86837\end{array}$ & $\begin{array}{l}.009 \\
.000\end{array}$ \\
\hline & & $20 \mathrm{sec}$ & $\begin{array}{l}10 \mathrm{sec} \\
30 \mathrm{sec}\end{array}$ & $\begin{array}{l}-4.0667^{*} \\
-6.5333^{*}\end{array}$ & $\begin{array}{l}.86837 \\
.86837\end{array}$ & $\begin{array}{l}.000 \\
.000\end{array}$ & $200 \mathrm{~g}$ & $\begin{array}{l}100 \mathrm{~g} \\
300 \mathrm{~g}\end{array}$ & $\begin{array}{l}2.7333^{*} \\
-1.3333\end{array}$ & $\begin{array}{l}.86837 \\
.86837\end{array}$ & $\begin{array}{l}.009 \\
.287\end{array}$ \\
\hline & & $30 \mathrm{sec}$ & $\begin{array}{l}10 \mathrm{sec} \\
20 \mathrm{sec}\end{array}$ & $\begin{array}{l}2.4667^{*} \\
6.5333^{*}\end{array}$ & $\begin{array}{l}.86837 \\
.86837\end{array}$ & $\begin{array}{l}.020 \\
.000\end{array}$ & $300 \mathrm{~g}$ & $\begin{array}{l}100 \mathrm{~g} \\
200 \mathrm{~g}\end{array}$ & $\begin{array}{c}4.0667^{*} \\
1.3333\end{array}$ & $\begin{array}{l}.86837 \\
.86837\end{array}$ & $\begin{array}{l}.000 \\
.287\end{array}$ \\
\hline & \multirow{3}{*}{ 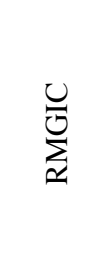 } & $10 \mathrm{sec}$ & $\begin{array}{l}20 \mathrm{sec} \\
30 \mathrm{sec}\end{array}$ & $\begin{array}{l}-2.3333 \\
3.8889^{*}\end{array}$ & $\begin{array}{l}1.43730 \\
1.43730\end{array}$ & $\begin{array}{l}.262 \\
.037\end{array}$ & $100 \mathrm{~g}$ & $\begin{array}{l}200 \mathrm{~g} \\
300 \mathrm{~g}\end{array}$ & $\begin{array}{c}1.4444 \\
-5.2222^{*}\end{array}$ & $\begin{array}{l}1.43730 \\
1.43730\end{array}$ & $\begin{array}{l}.583 \\
.005\end{array}$ \\
\hline & & $20 \mathrm{sec}$ & $\begin{array}{l}10 \mathrm{sec} \\
30 \mathrm{sec}\end{array}$ & $\begin{array}{l}2.3333 \\
6.2222^{*}\end{array}$ & $\begin{array}{l}1.43730 \\
1.43730\end{array}$ & $\begin{array}{l}.262 \\
.001\end{array}$ & $200 \mathrm{~g}$ & $\begin{array}{l}100 \mathrm{~g} \\
300 \mathrm{~g}\end{array}$ & $\begin{array}{l}-1.4444 \\
-6.6667^{*}\end{array}$ & $\begin{array}{l}1.43730 \\
1.43730\end{array}$ & $\begin{array}{l}.583 \\
.001\end{array}$ \\
\hline & & $30 \mathrm{sec}$ & $\begin{array}{l}10 \mathrm{sec} \\
20 \mathrm{sec}\end{array}$ & $\begin{array}{l}-3.8889^{*} \\
-6.2222^{*}\end{array}$ & $\begin{array}{l}1.43730 \\
1.43730\end{array}$ & $\begin{array}{l}.037 \\
.001\end{array}$ & $300 \mathrm{~g}$ & $\begin{array}{l}100 \mathrm{~g} \\
200 \mathrm{~g}\end{array}$ & $\begin{array}{l}5.2222^{*} \\
6.6667^{*}\end{array}$ & $\begin{array}{l}1.43730 \\
1.43730\end{array}$ & $\begin{array}{l}.005 \\
.001\end{array}$ \\
\hline \multirow{4}{*}{ \& } & \multirow{3}{*}{ 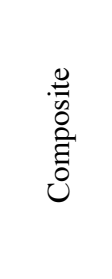 } & $10 \mathrm{sec}$ & $\begin{array}{l}20 \mathrm{sec} \\
30 \mathrm{sec}\end{array}$ & $\begin{array}{l}-1.6667 \\
-7.5556^{*}\end{array}$ & $\begin{array}{l}2.81530 \\
2.81530\end{array}$ & $\begin{array}{l}.826 \\
.038\end{array}$ & $100 \mathrm{~g}$ & $\begin{array}{l}200 \mathrm{~g} \\
300 \mathrm{~g}\end{array}$ & $\begin{array}{c}-6.6667 \\
-14.5556^{*}\end{array}$ & $\begin{array}{l}2.81530 \\
2.81530\end{array}$ & $\begin{array}{l}.072 \\
.000\end{array}$ \\
\hline & & $20 \mathrm{sec}$ & $\begin{array}{l}10 \mathrm{sec} \\
30 \mathrm{sec}\end{array}$ & $\begin{array}{c}1.6667 \\
-5.8889\end{array}$ & $\begin{array}{l}2.81530 \\
2.81530\end{array}$ & $\begin{array}{l}.826 \\
.120\end{array}$ & $200 \mathrm{~g}$ & $\begin{array}{l}100 \mathrm{~g} \\
300 \mathrm{~g}\end{array}$ & $\begin{array}{c}6.6667 \\
-7.8889^{*}\end{array}$ & $\begin{array}{l}2.81530 \\
2.81530\end{array}$ & $\begin{array}{l}.072 \\
.030\end{array}$ \\
\hline & & $30 \mathrm{sec}$ & $\begin{array}{l}10 \mathrm{sec} \\
20 \mathrm{sec}\end{array}$ & $\begin{array}{l}7.5556^{*} \\
5.8889\end{array}$ & $\begin{array}{l}2.81530 \\
2.81530\end{array}$ & $\begin{array}{l}.038 \\
.120\end{array}$ & $300 \mathrm{~g}$ & $\begin{array}{l}100 \mathrm{~g} \\
200 \mathrm{~g}\end{array}$ & $\begin{array}{c}14.5556^{*} \\
7.8889^{*}\end{array}$ & $\begin{array}{l}2.81530 \\
2.81530\end{array}$ & $\begin{array}{l}.000 \\
.030\end{array}$ \\
\hline & RMGIC & \multicolumn{10}{|c|}{ no statistically significant differences, where $\mathrm{p}$ value .088} \\
\hline
\end{tabular}

*. The mean difference is significant at the $£ .05$ level

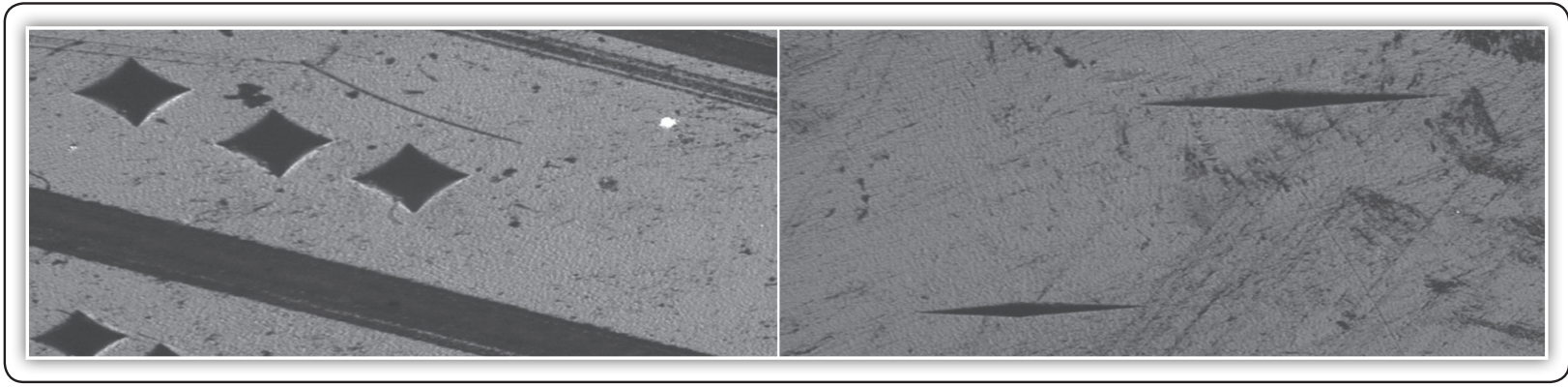

FIG (1) Group of Vickers indentations on composite and Knoop indentations on resin modified GIC at different loads and times. 


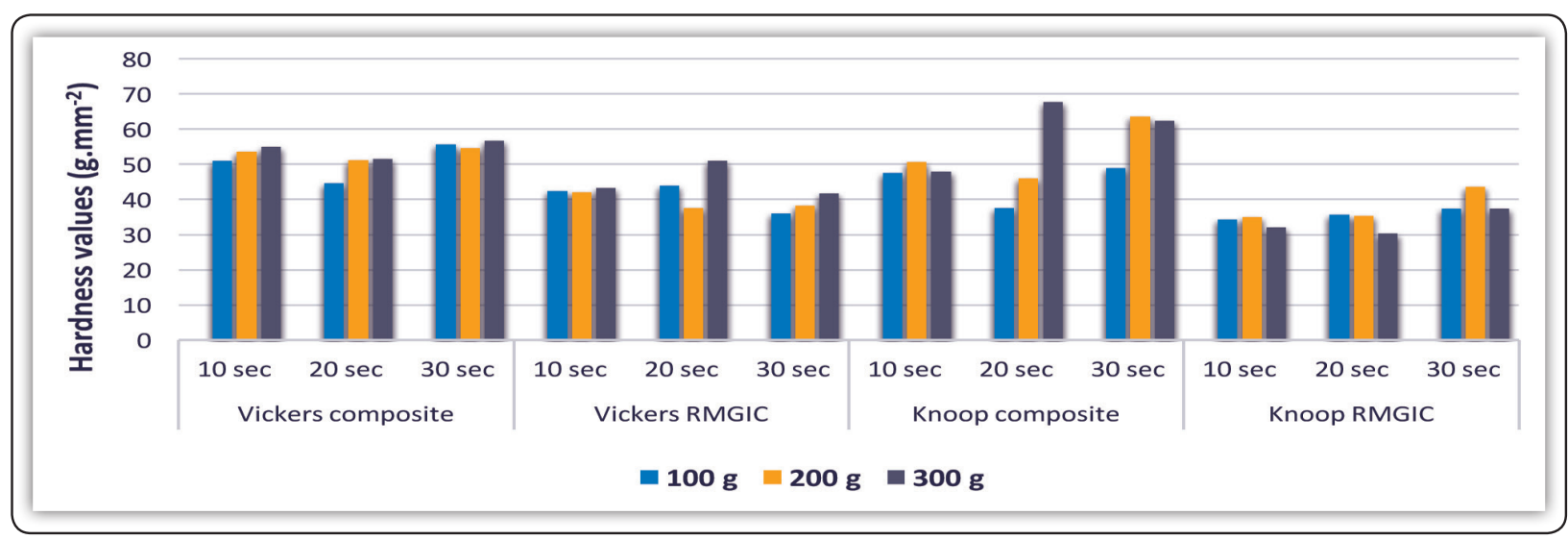

FIG (2) Comparative VHN and KHN values (Mean) of composite and RMGIC at different indentation loads and times.

\section{DISCUSSION}

Micro-hardness is a critical factor in predicting the materials performance and its clinical behavior as it considered an indicator of other mechanical properties as it provides both resistance of the surface of the material to local plastic deformation and a correlation to compressive and flexural strengths ${ }^{(18,19)}$.

Booth of Vickers and Knoop hardness testers can use successfully as an alternative to each other. However, knoop hardness has an advantage of less penetration into the specimen surface and cause less surface cracks in brittle materials, but its higher sensitivity to the surface texture than Vickers make it to less widely used ${ }^{(6,18)}$.

The application of different loads for different time, different hardness values are obtained, usually the hardness increased with decreases of depth of indentation, which represents a phenomenon called Indentation size effect (ISE) ${ }^{(2,20)}$.

However, The ISE effect was observed in ceramic, metallic and polymer materials but, in polymeric viscoelastic materials it cannot be explained by dislocation theory as in metal ${ }^{(20)}$. The ISE in viscoelastic materials may be related to the elastic deformation and recovery ${ }^{(12,20)}$. Also, the surface roughness may influence the deformation mechanisms and hardness obtained, so the specimen should be highly polished ${ }^{(21)}$.

The load response of viscoelastic polymers as composite and RMGIC depends on the load magnitude and duration. During loading the deformation of viscoelastic materials is time dependent and can grows even under constant load, and after unloading the deformation decreases gradually with time. That means the indentation area can increase with the time under the same $\operatorname{load}^{(22)}$. So, that can explain why there were statistically significant difference especially at long time loading.

The statistical analysis showed that the VHN and KHN values of composite and the VHN values of RMGIC depended on the indentation load. While, the KHN values of RMGIC load independent. The phenomenon that micro hardness values depend on the indentation load - the indentation size effect (ISE) - is well-known and has been observed in many materials ${ }^{(2)}$.

The composition of the material has a significant role in response to the applied static load where, composite is less flexible polymer and has high elastic modulus under static load because it consists of rigid backbone of Bis-GMA and Bis-EMA bulky monomers, while; RMGICs has HEMA in their composition which make them more flexible with 
observed decrease in their elastic modulus ${ }^{(22,23)}$. So, that explain why both Vickers and knoop microhardness results of RMGIC were lower than that of composite.

The Vickers results of composite revealed that the viscoelastic behavior was a function of time only and not of the stress magnitude. Initial loading caused an initial elastic response and was subsequently followed by a time-dependent viscoelastic deformation ${ }^{(22,23)}$. After load removal the recovery phase begins and consists of two stages: the first is an instantaneous elastic recovery and then a slower retarded elastic recovery ${ }^{(2,22,23)}$. And that can explain why there was no statistically significant differences between 200 and 300 g loads.

The viscoelastic materials were found to be the most prone to testing conditions, especially in the case of HEMA-containing material as $\mathrm{RMGIC}^{(22)}$. So, the increase of the applied stress resulted into an increase in the inelastic, irreversible strain of RMGIC and that explain why there was no statistical significant difference in their Knoop test ${ }^{(22,23)}$.

The duration of hardness test of viscoelastic material is very important factor, as, a short test, lasting only tens of seconds, often gives incomplete information, and long times can lead to significant errors ${ }^{(22)}$.The results of KHN value of composite there were no statistically significant difference for various loading times and that can explain why the test duration should be similar to the duration of delayed reversible processes or of the load action in applications ${ }^{(22)}$.

\section{CONCLUSIONS}

Within the limitation of this study, following conclusion is made:

1. For hardness test, the magnitude of applied load and the duration of test are critical factors as the test conditions can significantly affect the results.
2. The hardness of viscoelastic materials is time and load dependent.

3. For accurate hardness results no one load and time can use to characterize the material.

4. The indentation size effect (ISE) should be explored over a relatively wider range of applied test load and time, in order to obtain a complete understanding of this phenomenon.

5. The ISE cannot describe satisfactorily the change in hardness value of viscoelastic materials under different times and loads.

6. Uses of Vickers and Knoop hardness testers don't produce the same results.

\section{REFERENCES}

1. Faraoni -Romano JJ, Turssi CP,Serra MC: Concentrationdependent effect of bleaching agents on microhardness and roughness of enamel and dentin. J Amer Dent. 2007; 20(1):31-4.

2. Chuenarrom C, Benjakul P, Daosodsai P: Effect of indentation load and time on knoop and Vickers microhardness tests for enamel and dentin Mater Res. 2009; 12(4): 473-76.

3. Michels BD, Frischa GH: Microhardness of chalcogenide glasses of the system Se-Ge-As. J Mater Sci. 1982; 17(1): 329-34.

4. Gong $\mathrm{J}, \mathrm{Wu} \mathrm{J}$, Guan Z: Examination of the Indentation Size Effect in Low-load Vickers Hardness Testing of Ceramics. J Euro Ceram Socie. 1999; 19(1) 2625-31.

5. Jiang D: Recent progresses in the phenomenological description for the indentation size effect in microhardness testing of brittle ceramics. J Advanc Ceram.2012; 1(1): $38-49$.

6. Gutiérrez-Salazar M, Reyes-Gasga J: Microhardness and chemical composition of human tooth. J Mater Res. 2003; 6(3):367-73

7. Sebastina S, Khadar M: Microhardness indentation size effect studies in $60 \mathrm{~B}_{2} \mathrm{O}_{3}=(40-\mathrm{x}) \mathrm{PbO}-\mathrm{xMcl}_{2}(\mathrm{M}=\mathrm{Pb}$, Cd) glasses. J Mater Sci. 2005; 40(1): 1655-59.

8. Mukhopadhyay NK, Paufler P: Micro- and nanoindentation techniques for mechanical characterization of materials. Inter Mater Rev. 2006; 41(1): 209-45. 
9. Sangwal K: Review: Indentation size effect, indentation cracks and microhardness measurement of brittle crystalline solids - some basic concepts and trends. Cryst Res Technol. 2009; 44(1): 1019-37.

10. Petrík J, Palfy P, Mikloš V, Horváth M, Havlík M: The Influence of Operators and Applied Load on MicroHardness of the Standard Block. Acta Polytechn Hungari. 2014; 11(9): 183-96.

11. Low IM: Effects of load and time on the hardness of a viscoelastic polymer. Mater Res Bullet. 1998; 33(12):1753-58.

12. Tarkanian ML, Neumann JP, Raymond L: Determination of the temperature dependence of $\{100\}$ and $\{112\}$ slip in tungsten from Knoop hardness measurements. In: The Science of Hardness Testing and Its Research Application. Westbook JH, Conrad H, Eds. Amer Soci for Met. 1973; 3(7): 187-98

13. Quinn GD: Hardness testing of ceramics. Advan Mater and Proce. 1998; 154 (2): 25-7.

14. Ren XJ, Hooper RM, Griffiths C: Indentation Size Effect in Ceramics: Correlation with H/E. J Mater Scie Lett. 2003; 22 (1):1105- 06.

15. Sangwal K, Surowska B, Błaziak P: Analysis of the Indentation Size in the Microhardness Measurement of some Cobalt-based Alloys. Mater Chemis and Phys. 2002; 77(2):511-20.

16. Bala O, Arisu HD, Yikilgan I, Arslan S, Gullu A: Evaluation of Surface roughness and hardness of different glass ionomer cements. Eur J Dent. 2012; 6 (1): 79-86.
17. ERDEMIR U, yILDIZ E, EREN MM, OZEL S: Surface hardness evaluation of different composite resin materials: influence of sports and energy drinks immersion after a short-term period. J Appl Oral Sci. 2013; 21(2): 124-31.

18. Yoldas O, Akova T, Uysal H: Influence of Different Indentation Load and Dwell Time on Knoop Microhardness Tests for Composite Materials. Polym Testin.2004; 23(1): 343-46.

19. Peskersoy C, Culha O: Comparative Evaluation of Mechanical Properties of Dental Nanomaterials. J Nanometer. 2017; 2(17): 1-8.

20. Balos S, Sidjanin L, Pilic B: Indentation Size Effect in Auto polymerized and Microwave Post Treated Poly (methyl methacrylate) Denture Reline Resins. Acta Polytech Hung. 2014; 11(7): 239-49.

21. Han CS, Hartmaier A, Gao H, Huang Y: Discrete Dislocation Dynamics Simulations of Surface Induced Size Effects in Plasticity. J Mater Scie and Eng.2006; 415(17): 225-33.

22. Mencík J, Hong He L, Nemecek J: Characterization of viscoelastic-plastic properties of solid polymers by instrumented indentation. Polymer Testing. 2011; 30(12) 101-109

23. Lakes D, Papadogiannis RS, Tolidis YK: Mechanical viscoelastic behavior of dental adhesives. Dent Mater 2013; 29(5): 693-701. 
